\title{
Acute peripheral pulmonary embolism attributed to autoimmune haemolytic anaemia: a case report
}

\author{
Jing Xu, Liang Wang and Fadong Chen ${ }^{*}$
}

\begin{abstract}
Background: PE (pulmonary embolism) is a life-threatening complication rarely seen in the AlHA (autoimmune haemolytic anaemia) patients. Herein we reported a rare and serious AlHA-PE patient characterised by extensive peripheral pulmonary embolism on CTPA.

Case presentation: A 59-year-old woman presented to our ED (emergency department) complaining of acute chest pain and dyspnea. During her presentation in ED she experienced a sudden syncope and soon developed CA (cardiac arrest). Laboratory studies showed a increase of CK-MB,troponin T,myoglobin and D-dimer. Computed tomography pulmonary angiography (CTPA) showed no large central or segment pulmonary emboli but increased RV (right ventricle)size,enlarged main pulmonary artery and invisible peripheral pulmonary artery. She was diagnosed with acute PE and alteplase was delivered intravenously. After thrombolytic therapy she remained hypotension and developed worsening anaemia. Detailed examination for anaemia revealed AlHA. She was discharged in a stable condition after 5 weeks with methylprednisolone and warfarin. $\mathrm{Hb}$, D-dimer and transthoracic echocardiography showed complete recovery at 3-months follow up.

Conclusion: PE attributed to AlHA is characterized by subsegment and distal pulmonary artery embolism which is easily neglected but always life-threatening. This case also highlights the PE as a secondary diagnosis should be evaluated comprehensively in order to identify the underlying pathogenesis.
\end{abstract}

Keywords: Pulmonary embolism, Anemia, Hemolytic, Autoimmune

\section{Background}

AIHA is a rare autoimmune disease with an estimated annual incidence of 1 to 3 per 100,000 individuals [1]. VTE (Venous thromboembolism) such as PE is a life-threatening complication of AIHA which contributed to the death of $3-10 \%$ in these patients [2], thus how to timely identify and appropriately manage AIHA-PE patients remains a clinical challenge. Past studies had been confined to case reports or small patient series, while the clinical features of PE attributed to AIHA are undermined. In this report we present a

\footnotetext{
* Correspondence: chenfadong0819@163.com

Department of Cardiology, Shanghai East Hospital,Shanghai Tongji University School of Medicine, Shanghai, China
}

rare case experiencing syncope and cardiogenic shock was finally diagnosed with AIHA-PE.

\section{Case presentation}

A 59-year-old woman presented to our ED complaining of acute chest pain and dyspnea. She had vomited once, associated with fatigue and dizziness. She had no medical history. Vital signs at ED admission were stable: body temperature $37.3^{\circ} \mathrm{C}$; BP (blood pressure) $120 / 68$ $\mathrm{mmHg}$; heart rate 95 beats/min;respiratory rate 23 breaths/min;oxygen saturation $84.3 \%$ on room air. Cardiac examination showed high-pitched P2. Abdominal findings were unremarkable. There was no lower limbs edema. Initial blood analysis revealed $\mathrm{Hb}$ (haemoglobin)

(c) The Author(s). 2020 Open Access This article is licensed under a Creative Commons Attribution 4.0 International License, which permits use, sharing, adaptation, distribution and reproduction in any medium or format, as long as you give appropriate credit to the original author(s) and the source, provide a link to the Creative Commons licence, and indicate if changes were made. The images or other third party material in this article are included in the article's Creative Commons licence, unless indicated otherwise in a credit line to the material. If material is not included in the article's Creative Commons licence and your intended use is not permitted by statutory regulation or exceeds the permitted use, you will need to obtain permission directly from the copyright holder. To view a copy of this licence, visit http://creativecommons.org/licenses/by/4.0/. The Creative Commons Public Domain Dedication waiver (http://creativecommons.org/publicdomain/zero/1.0/) applies to the data made available in this article, unless otherwise stated in a credit line to the data. 
was $9.2 \mathrm{~g} / \mathrm{dl}$ with white cell count $15.68 \times 10^{9} / \mathrm{L}$,neutrophils $74.8 \%$ and platelet count $334 \times 10^{9} / \mathrm{L}$; Cardiac enzymes test showed CK-MB was $1.96 \mathrm{ng} / \mathrm{ml}$, troponin $\mathrm{T}$ was $0.046 \mathrm{ng} / \mathrm{ml}$, myoglobin was $21.23 \mathrm{ng} / \mathrm{ml}$ and a high level of D-dimer $(6.38 \mathrm{mg} / \mathrm{l})$; A 12-lead ECG (Fig. 1a) confirmed a sinus rhythm with ST depression in II,III, aVF,V4-V6.

About $6 \mathrm{~h}$ after admission,she suddenly developed syncope on the way to the toilet. Her heart rate increased to 100-130beats/min with hypotension (BP 80-90/55-60 $\mathrm{mmHg}$ ) and low oxygen saturation $(85-90 \%$ on nasal oxygen inhalation). Reexamined 12-lead ECG (Fig. 1b) exhibited ST-segment elevation in aVR and depression futher in II,III,aVF,V4-V6. Laboratory studies showed a further increase of CK-MB $(3.76 \mathrm{ng} / \mathrm{ml})$,troponin $\mathrm{T}$ $(1.75 \mathrm{ng} / \mathrm{ml})$,myoglobin $(47.28 \mathrm{ng} / \mathrm{ml})$ and D-dimer $(7.36$ mg/l). To exclude an acute PE, emergent CTPA (Fig. 2a) was performed showing increased RV size,flattened interventricular septum,enlarged main pulmonary artery and invisible peripheral pulmonary artery. No large central or segment pulmonary emboli was detected. She suddenly developed bradycardia and following CA on the way to the cardiac care unit for further treatment. Given the patient's previous findings (ECG,CTPA,laboratory studies) and clinical status, the diagnosis of acute PE (high risk) was established, $50 \mathrm{mg}$ alteplase was delivered intravenously within $1 \mathrm{~h}$ and cardiopulmonary resuscitation was promptly initiated. Meanwhile,she was intubated receiving mechanical ventilation. She recovered consciousness $2 \mathrm{~h}$ after uninterrupted CPR. At the second day,her clinical symptoms markedly ameliorated, heart rate and oxygen saturation recovered to $70-80 \mathrm{bpm}$

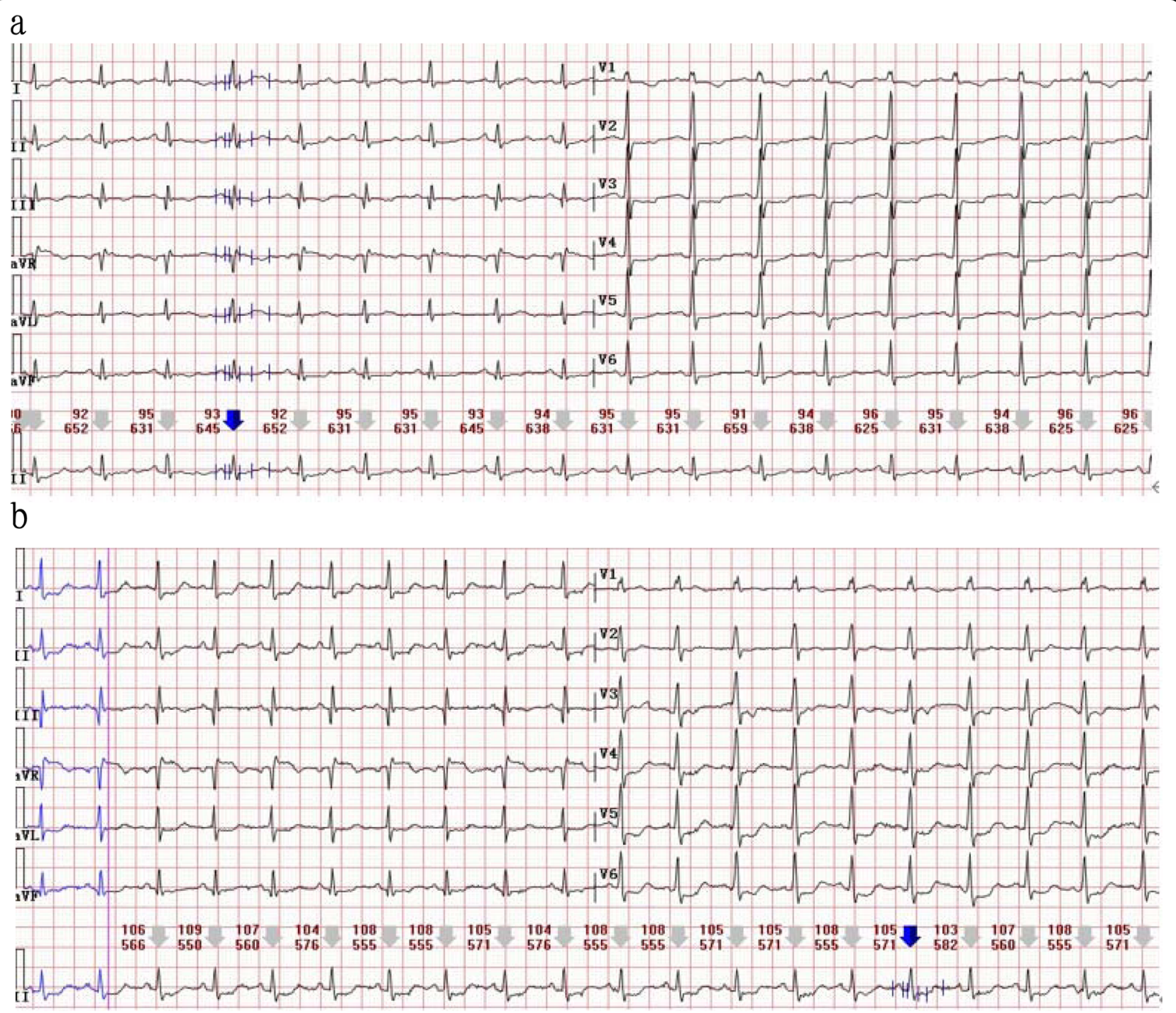

Fig. 1 a Twelve-lead ECG at admission showing sinus rhythm (95 bpm) with ST depression in II,III,aVF,V4-V6. b Twelve-lead ECG at syncope showing ST-segment elevation in aVR and depression futher in II,III,aVF,V4-V6 

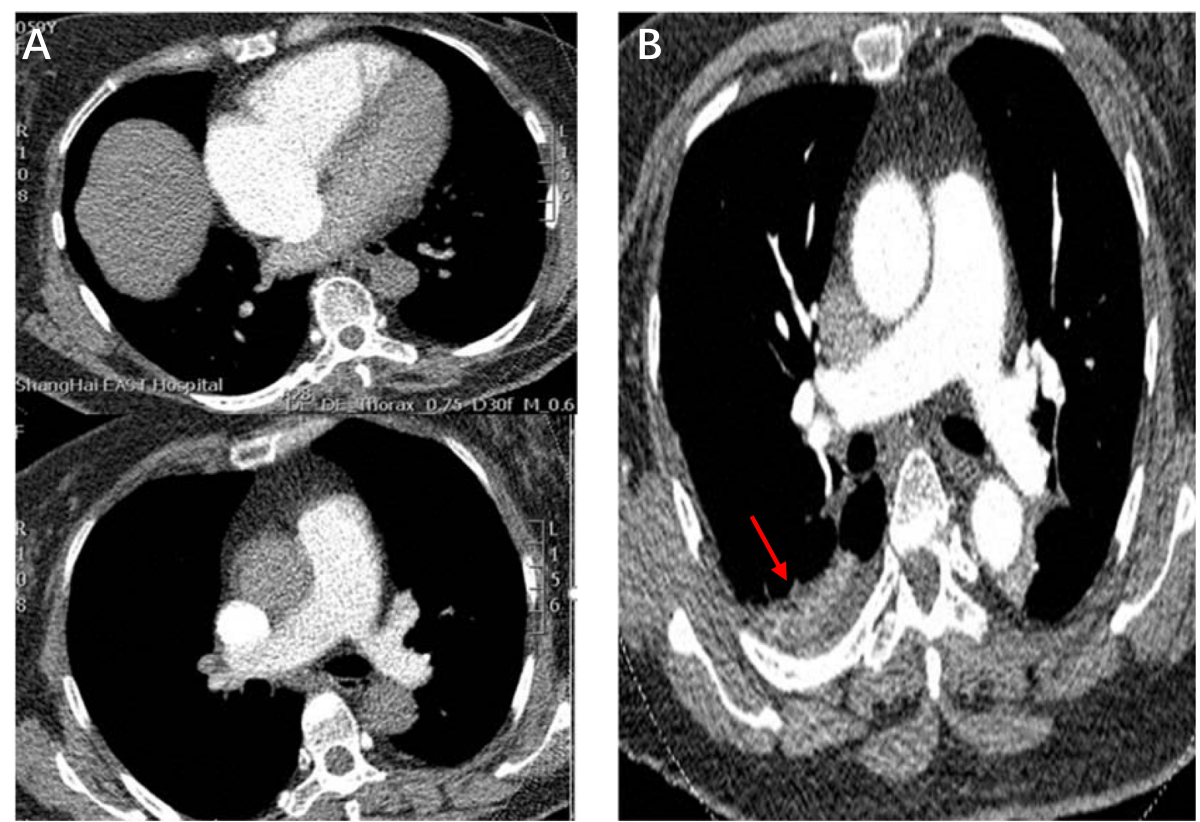

Fig. 2 a CTPA at emergency department showing increased right ventricle size,flattened interventricular septum,enlarged main pulmonary artery and invisible peripheral pulmonary artery. No large central or segment pulmonary emboli was detected. b CTPA after thrombolytic therapy showing RV pressure overload ameliorated,peripheral pulmonary artery was visible and a little unilateral pleural effusion close to rib (highlighted by a red arrow)

and $95 \%$ without mechanical ventilation,respectively. The repeat CTPA (Fig. 2b) revealed RV size diminished and peripheral pulmonary artery was visible. TTE (transthoracic echocardiogram) (Fig. 3) revealed dilated right heart with increased pulmonary arterial systolic pressure (PASP $40 \mathrm{mmHg}$ ). She remained hypotension and developed worsening anaemia of $\mathrm{Hb} 57 \mathrm{~g} / \mathrm{l}$ without any bleeding. Further laboratory examination aiming at anaemia revealed the percentage of reticulocyte was $9.7 \%$, absolute reticulocyte count was $0.186 \times 10^{12} / \mathrm{L}$, total bilirubin was $40.9 \mathrm{umol} / \mathrm{L}$ with unconjugated bilirubin $28.7 \mathrm{umol} /$ l,lactate dehydrogenase was $6669.70 \mathrm{U} / \mathrm{L}$. In addition, the patient's direct antiglobulin test was reactive for IgG and was negative for complement. Bone marrow examination, a search for lymphoproliferative disorders and immune diseases were all negative.

On the fifth day of hospitalization,she was transfused with 2 units of Washed Red Blood Cells due to decreased $\mathrm{Hb}$ of $49 \mathrm{~g} / \mathrm{l}$,which fell further to $34 \mathrm{~g} / \mathrm{l}$ after transfusion therapy. Intravenous corticosteroids (methylprednisolone $60 \mathrm{mg}$ bid) plus immunoglobulin (IVIg $10 \mathrm{~g}$ qd) were added to her regimen. The anaemia improved progressively during the following days (Fig. 4).

She was discharged in a stable condition after 5 weeks with oral methylprednisolone $(40 \mathrm{mg} \mathrm{qd}$ ) and warfarin $(2.5 \mathrm{mg} \mathrm{qd})$. At 3-months follow up,the patient was asymptomatic and presented a complete recovery with $\mathrm{Hb}$ $141 \mathrm{~g} / \mathrm{l}$ and normal D-dimer. TTE showed a complete disappearance of initial abnormalities. The patient' current medication including methylprednisolone $(4 \mathrm{mg} \mathrm{qd})$ and warfarin $(2.5 \mathrm{mg} \mathrm{qd})$.

\section{Discussion and conclusion}

AIHA is an acquired haemolysis caused by the host's immune system acting against its own red cell antigens. It can occur at any age but incidence rises with increasing age. AIHA is divided into warm antibody (wAIHA), cold antibody-mediated (cAIHA) or mixed AIHA. Approximately half are primary (idiopathic) AIHA and half are secondary to associated disorders, including neoplasia, infection,immune dysregulation or drug induced [3].

The increased risk of PE associated with AIHA is an increasing matter of concern due to significant morbidity and mortality. As early as the 1960s, a review of 47 patients found the most common cause of death was PE [4]. However, the clinical features of PE attributed to AIHA are undermined. In 2015,Andrew Woodson [5] reported a 52year-old man presenting as progressive fatigue, weakness and palpitations was diagnosed with AIHA-PE.He experienced profound haemodynamic compromise while no large central emboli,only small pulmonary emboli in bilateral subsegmental arteries was observed on CTPA. Our case initially presenting with chest pain and syncope was considered as PE due to increased RV loading, broadened main pulmonary artery and invisible peripheral pulmonary vessels on CTPA. In addition, the diagnosis of PE (high risk) could be met in this patient for typical clinical presentations (chest pain,syncope and CA),the laboratory tests(D-dimer, 

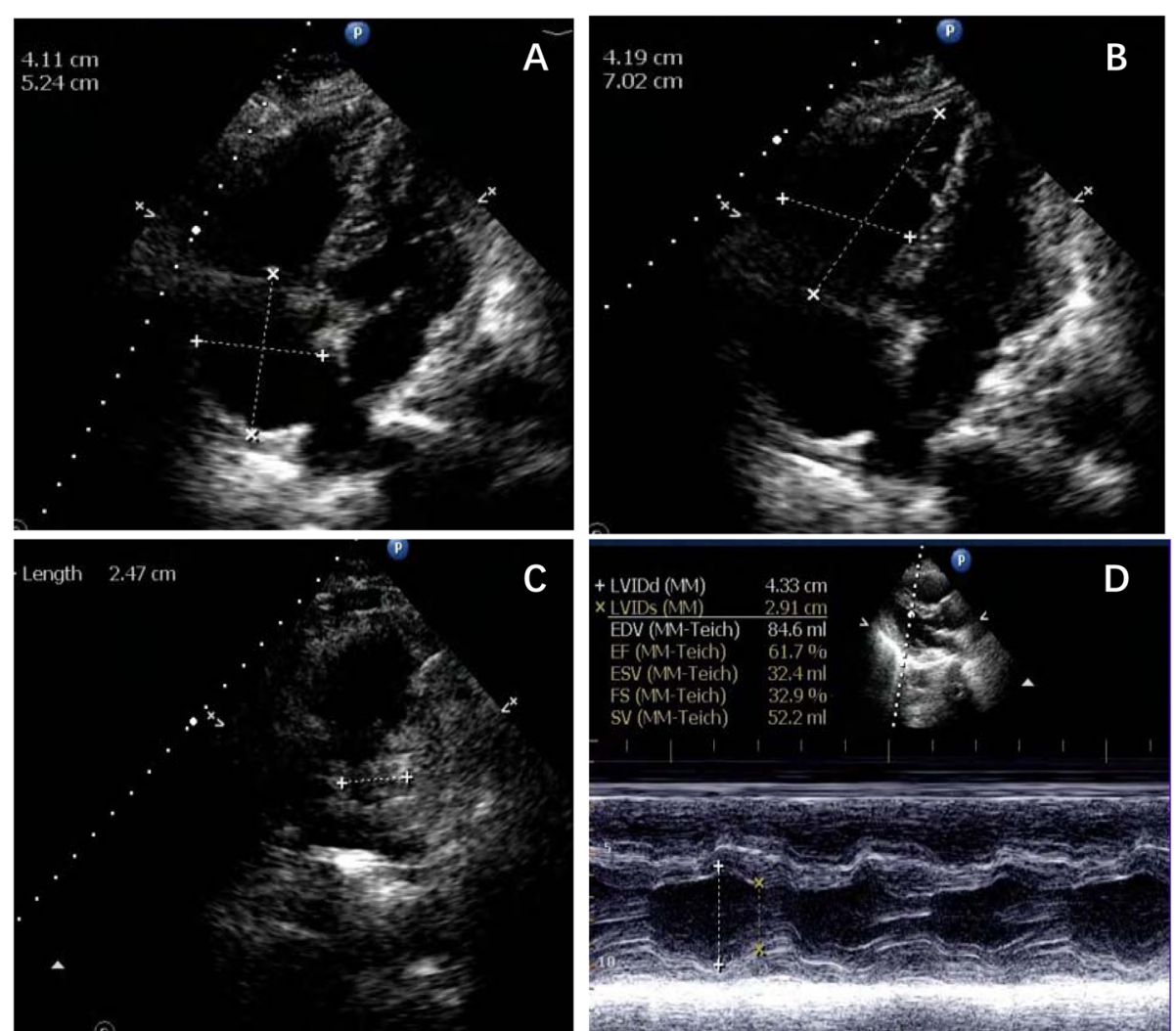

Fig. $3 T T E$ at bedside after thrombolytic therapy. a Dilated right atrium $(41 \mathrm{~mm} \times 52 \mathrm{~mm})$. b Dilated right ventricle $(42 \mathrm{~mm} \times 70 \mathrm{~mm})$. c Pulmonary artery diameter $(25 \mathrm{~mm})$ was measured by TTE. $\mathbf{d}$ Left ventricular size and ejection fraction were measured by TTE

oxygen saturation, troponin $\mathrm{T}$ ) and echocardiogram (dilated right heart and increased PASP). Our case indicated that PE attributed to AIHA is characterized by subsegment and distal pulmonary artery embolism, which is easily neglected but always life-threatening,thus needing us to detect and manage early to improve clinical outcomes.

This case report highly suggested comprehensive evaluation for the cause of PE in patients with first occurrence.
Major risk factors for PE include surgery,active cancer, immobility, trauma or fracture, pregnancy, and estrogen therapy. In our case,it is paradoxical that after thrombolytic therapy, the patient remained hypotension while other evidence confirmed thrombolytic is effective as the clinical symptoms markedly improved, oxygen saturations and heart rate were normalized, D-dimer rised rapidly and following fell gradually, RV pressure overload ameliorated

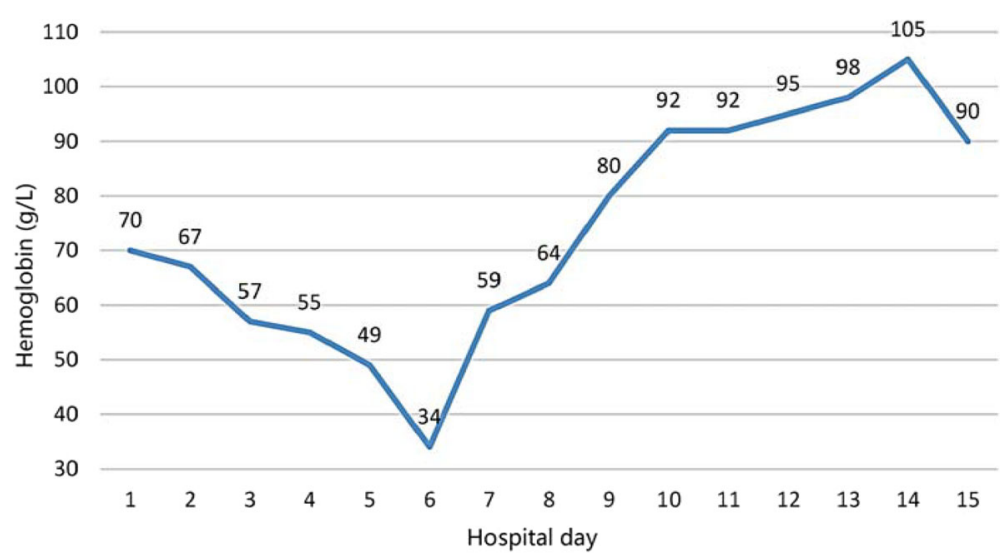

Fig. 4 The Change of hemoglobin throughout the course of hospitalization. At HD5, the patient was transfused with 2 units of Washed Red Blood Cells. Methylprednisolone and immunoglobulin were initiated on HD7 
on CTPA. Besides, the patient admitted in ED with low level of hemoglobin $(92 \mathrm{~g} / \mathrm{l})$ and decreased futher $(57 \mathrm{~g} / \mathrm{l})$ without any hemorrhage after thrombolytic therapy,which intrigue us to investigate the real etiologe of PE. Primary wAIHA is finally diagnosed based on further laboratory examination. This case highly suggested the patients presenting with PE should be systematically investigated with scrutiny in order to explore the potential diseases.

The AIHA patients complicated by PE should be treated aggressively as early as possible. When suffering from haemodynamic compromise, the patients should be administered with thrombolytics immediately [6]. First line treatment for primary wAIHA is oral prednisolone. Intravenous methylprednisolone and immunoglobulin may be considered in severe, life-threatening cases [7]. In our case,intravenous methylprednisolone and IVIg were added to her regimen when $\mathrm{Hb}$ fell further after transfusion. Transfusion should be treated with caution due to the risk of hemolytic transfusion reactions caused by alloantibodies of AIHA. Given the higher risk of thrombosis, long-term anticoagulation should be advised [8]. Despite the improved safety of Non-vitamin $\mathrm{K}$ antagonist oral anticoagulants (NOACs) compared with Vitamin K antagonists (VKAs) for extended anticoagulation of acute PE, treatment with NOACs is not without risk [9]. This patient was administered with warfarin since VKAs have been the gold standard in oral anticoagulation. NOACs may be an alternative to VKAs in this setting but there is no evidence-based practice $[7,9]$.

In conclusion, We present a rare case of previously healthy female patient experiencing a sudden syncope and following cardiac arrest for PE attributed to AIHA. Upon encountering suspected high-risk PE based on clinical probability,which is characterized by peripheral pulmonary emboli and severe anemia, AIHA should be considered. Close attention as well as timely treatment play a crucial role.

\footnotetext{
Abbreviations

AlHA: Autoimmune haemolytic anaemia; BP: Blood pressure; CA: Cardiac arrest; CTPA: Computed tomography pulmonary angiography; ED: Emergency department; Hb: Haemoglobin; NOACs: Antagonist oral anticoagulants; PE: Pulmonary embolism; RV: Right ventricle;

TTE: Transthoracic echocardiogram; VKAs: Vitamin K antagonists; VTE: Venous thromboembolism
}

\section{Acknowledgements}

None.

\section{Authors' contributions}

JX reviewed the literature and drafted the manuscript; LW was the patient's cardiologist and reviewed the literature;FDC was responsible for the revision of the manuscript for important intellectual content. All authors issued final approval for the version to be submitted.

\section{Funding}

This work was supported by a grant from Top-level Clinical Discipline Project of Shanghai Pudong District (PWYgf2018-02). Funding support was used to collect, analyze the data and the travel-related expenses for patient followup.

Availability of data and materials

The datasets used in the case are available from the corresponding author upon reasonable request.

\section{Ethics approval and consent to participate}

This study was approved by the Ethical Committee of Shanghai east hospital affiliated to Tongji University. Written informed consent was obtained from individual participant.

\section{Consent for publication}

Written informed consent was obtained from the patient for publication of this case report and any accompanying images. A copy of the written consent is available for review by the Editor-in-Chief of this journal.

\section{Competing interests}

The authors declare that they have no competing interests.

Received: 18 December 2019 Accepted: 27 February 2020

Published online: 04 March 2020

References

1. Liebman HA, Weitz IC. Autoimmune Hemolytic Anemia. Med Clin North Am. 2017;101(2):351-9.

2. Pullarkat $\mathrm{V}, \mathrm{Ngo} \mathrm{M}$, Iqbal S. Detection of lupus anticoagulant identifies patientswith autoimmune haemolytic anaemia at increased risk for venous thromboembolism. Br J Haematol. 2002;118(4):1166-9.

3. Hill QA, Stamps R, Massey E, et al. The diagnosis and management of primary autoimmune haemolytic anaemia. Br J Haematol. 2017;176(3):395411.

4. Lecouffe-Desprets M, Néel A, Graveleau J, et al. Venous thromboembolism related to warm autoimmune hemolytic anemia: a case-control study. Autoimmun Rev. 2015;14(11):1023-8.

5. Woodson KA, Lee Y, Gopalratnam K, et al. Adding insult to injury: autoimmune haemolytic anaemia complicated by pulmonary embolism. BMJ Case Rep. 2016;2016:bcr2015213575.

6. Gao JP, Ying KJ. Thrombolysis during extended cardiopulmonary resuscitation for autoimmune-related pulmonary embolism. World J Emerg Med. 2015;6(2):153-6.

7. Jäger U, Barcellini W, Broome CM, et al. Diagnosis and Treatment of Autoimmune Hemolytic Anemia in Adults: Recommendations From the First International Consensus Meeting. Blood Rev. 2019;12(5):100648.

8. Audia S, Bach B, Samson M, et al. Venous thromboembolic events during warm auto immune hemolytic anemia. PLoS One. 2018;13(11):e0207218.

9. Konstantinides SV, Meyer G, Becattini C, et al. 2019 ESC guidelines for the diagnosis and management of acute pulmonary embolism developed in collaboration with the European Respiratory Society (ERS). Eur Heart J. 2020; 41(4):543-603.

\section{Publisher's Note}

Springer Nature remains neutral with regard to jurisdictional claims in published maps and institutional affiliations.
Ready to submit your research? Choose BMC and benefit from:
- fast, convenient online submission
- thorough peer review by experienced researchers in your field
- rapid publication on acceptance
- support for research data, including large and complex data types
- gold Open Access which fosters wider collaboration and increased citations
- maximum visibility for your research: over $100 \mathrm{M}$ website views per year
At BMC, research is always in progress.
Learn more biomedcentral.com/submissions 